\title{
Agricultural Sprinkler for Irrigation System
}

\author{
Nirali Hemant Patel \\ Student, Electronics and communication \\ Charotar University of Science and Technology, \\ CHARUSAT. Anand, India.
}

\author{
Chintan Rajnikant Prajapati \\ Student, Mechatronics \\ G.H. Patel College of Engineering and Technology, \\ GCET. Anand, India.
}

\begin{abstract}
In this review paper, the need to irrigate farms or gardens by a way which will replace the natural rainfall when not available led to the planning and construction of the sprinkler irrigation system. During this study, different types of sprinkler irrigation system was taken into study with their design, construction and installation. The planning was supported employing a rotating system to irrigate a little size plot which provides a suitable scientific basis for correct water scheduling, evaluation of the system and minimizing water wastage and runoff. It had been designed for various crops. The importance of the designing and installation is to equip the irrigation research field of the University with irrigation field demonstration practice facilities that could be used.
\end{abstract}

Keywords-Agricultural, Crops, Construction, Design, Irrigation, Sprinkler.

\section{INTRODUCTION}

Irrigation is a man-made method of water application to soil to reinforce the assembly of crops. Irrigation water is supplied to supplement the water available from rainfall, soil moisture and therefore the capillary rise of spring water. In many areas of the planet, the quantity of rainfall isn't capable meet the moisture requirements of crops. Hence, successful crop production is very much requiring adequate provision for irrigation (Benami \& Ofen, 1983; Jensen, 1980; Michael, 2005). consistent with Sharma and Sharma, (2004), the role of irrigation systems is often categorized as direct and indirect benefits. ${ }^{[1]}$ The direct benefits include; increase in crop production output through higher yield to achieve selfsufficiency in food, cultivation of money crops, land value appreciates manifold which makes wealthy the land holders and domestic water system to towns and villages (like within the cities like Delhi, Jaipur, Bikaner and Chandigarh depend upon canal water for public water supply in INDIA), hydropower generation at dam site and canal falls. and therefore the indirect benefits are; increase in gross domestic product of the country, increase in revenue from nuisance tax on food grains, increase employed, retards migration to cities for livelihood, farm laborers get higher wages, creation of more jobs/incomes and rise to whole array of agro-based industries. Sprinkler irrigation is an important improvement over conventional surface irrigation. It stimulates natural rainfall by spreading water within the sort of rain uniformly over the land surface when needed at required quantity during a uniform pattern. Water is applied at a rate but the infiltration rate of the soil so on avoid surface runoff from irrigation. Sprinkler irrigation systems is suitable for undulating lands, lack of water availability, sandy or shallow soils and where uniform application of water.

Drip irrigation is a basic and an artificial method of supplying water to the roots of the plant. it's also called micro irrigation.
In past few years there's a rapid climb during this system. The user communicates with the centralized unit via SMS or text. The centralized unit communicates with the system through SMS or text which can be received by the GSM with the assistance of the SIM card. The GSM sends this particular data to ARM7 which is additionally continuously receives the information from sensors in some sort of codes. After processing the whole, this data is displayed on the LCD. ${ }^{[3]}$ Thus briefly whenever the system receives the activation command from the subscriber it checks all the sector conditions and provides an in depth feedback to the user and waits for an additional activation command to start out the motor. The motor is controlled by an easy manipulation within the internal structure of the starter. The starter coil is being indirectly activated via a transistorized relay circuit. When the motor is started, a continuing monitoring on soil moisture and water level is completely done \& once the soil moisture is reached to sufficient level the motor is automatically turned off $\&$ a message is send to subscriber that the motor is turned off The water level indicator indicates three levels which are low, medium, high and also empty tank.

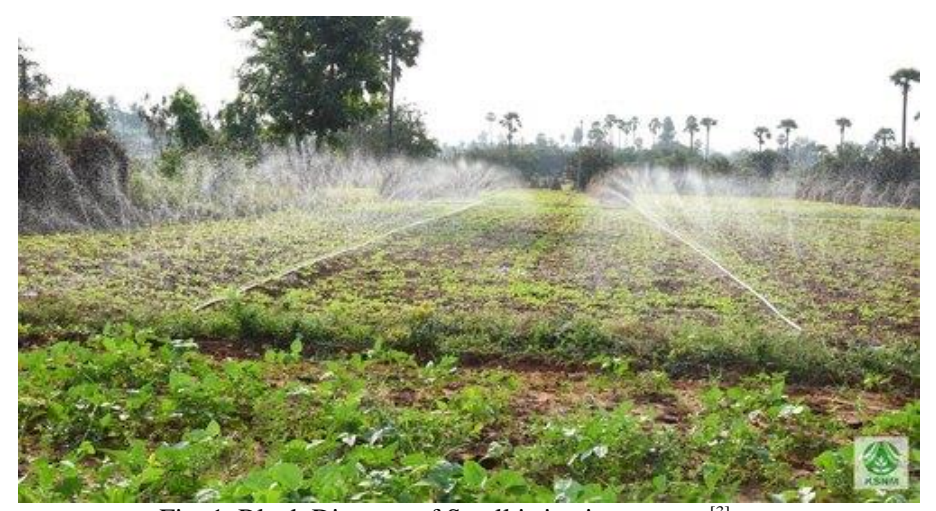

Fig. 1. Block Diagram of Small irrigation system ${ }^{[3]}$

\section{TYPES OF SPRINKLER}

1) Small irrigation system ${ }^{[12]}$

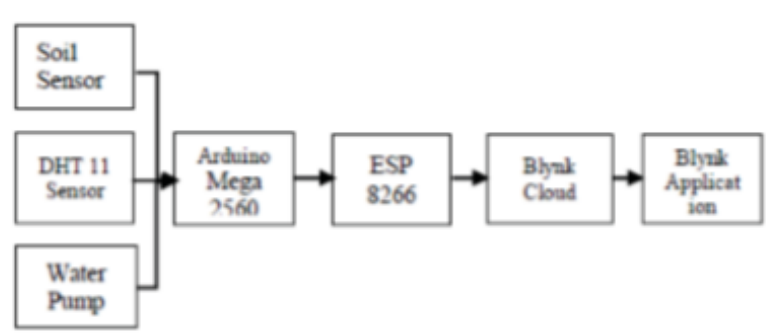

Fig. 2. Block Diagram of Small irrigation system ${ }^{[12]}$ 
In this particular type, the temperature value is kept on change from a fixed range of values. The humidity value is also kept changing from a range of value along with the soil moisture values. The height is taken into consideration from the starting of the experiment in terms of percentage along with the diameter, so that it can conclude that the plant is healthy. It takes the colour of leaves into consideration which represents the nature of good plant. Moreover, from the value of the soil moisture it shows that it is in good condition and this small irrigation system is very good as it waters the plant with the correct amount of water. Hence, it can be said that the plant is not over watered or less watered.

\section{2) Automatic Irrigation System ${ }^{[9]}$}

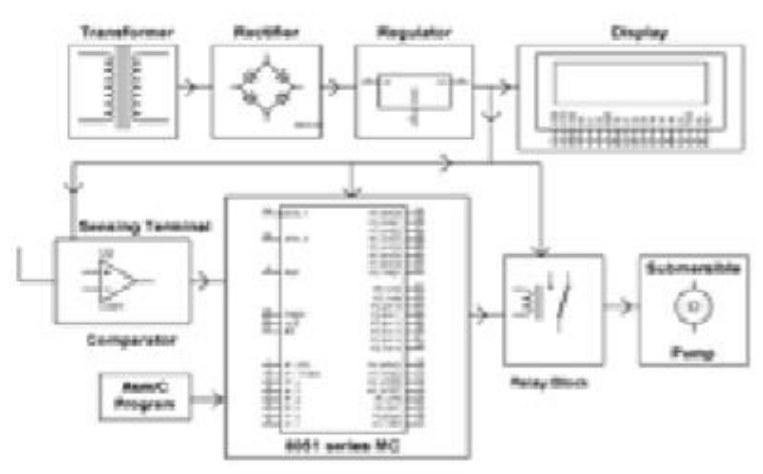

Fig. 3. Block diagram of Automatic Irrigation System ${ }^{[9]}$

The soil moisture sensors which are nothing but copper strands are inserted within the soil. The soil sensing arrangement is used to measures the conductivity of the soil. Wet soil is going to be more conductive than dry soil. The soil sensing arrangement module features a comparator in it. The voltage from the prongs and thus the predefined voltage is compared and therefore the output of the comparator is high only the soil condition is dry. This output from the soil sensing arrangement is given to the analogue input pin of the microcontroller.

The microcontroller continuously monitors the analogue input pin. When the moisture within the soil is above the sting, the microcontroller displays a message mentioning the same and thus the motor is off. When the output from the soil sensing arrangement is high i.e. the moisture of the soil is a smaller amount. this may trigger the microcontroller and displays an appropriate message on the LCD and therefore the output of the microcontroller, which is connected to the bottom of the transistor, is high. When the transistor is turned on, the relay coil gets energized and activates the motor. The LED is additionally turned on and acts as an indicator. When the moisture of the soil reaches the edge value, the output of the soil sensing arrangement is low and therefore the motor is turned off.

\section{3) Periodic Move Sprinkler Systems ${ }^{[5]}$}

A periodic move system is about during a fixed location for a specified length of your time to use a required depth of water. this is often referred to as the irrigation set time. After an irrigation set, the lateral or sprinkler is moved to subsequent set position. Applications range from 50\% - 75\%.

\section{4) Continuous (Self) Move Sprinkler System [5]}

Center pivot systems contains one lateral supported by towers with one end anchored to a hard and fast pivot structure and therefore the other end continuously traveling the pivot point while applying water this system irrigates a circular field unless finish guns and swing lines square measure cycled on in corner areas to irrigate additional of a sq. field. The water is equipped from the supply to the lateral through the pivot. The lateral pipe with sprinklers is supported on drive units. The drive units' square measure, usually battery-powered by hydraulic water drives or electrical motors. Numerous operative pressures and configurations of mechanical device heads or nozzles (types and spacing) square measure placed on the lateral. Sprinkler heads with nozzles could also be high or low impact, gear driven, or one among many low spray heads. a better discharge, part circle gun is usually used at the acute end (end gun), of the lateral to irrigate the outer fringe of the lateral. Each tower which is usually mounted on rubber tires, features a power device designed to propel the system round the pivot point. the foremost common power units include motor, hydraulic water drive, and hydraulic oil drive. When feasible, agricultural operators are converting from portable sprinkler systems and travelers to put in center pivot systems. Many improvements are remodeled the years. This includes the corner arm system. Some models contain another swing lateral unit that expands to succeed in the corners of a field and retracts to a trailing position when the system is along the sector edge. When the corner unit starts, discharge flow altogether other heads is reduced. Overall field distribution uniformity is affected with the corner arm. Typically, $85 \%$ of maintenance is spent maintaining the corner arm unit itself. thanks to less than adequate maintenance in corner systems operating all the time, total field application uniformity is reduced even further. Many techniques are developed to scale back energy used, lower system flow capacities, and maximize water use efficiency. These include using Low Energy Precision Application (LEPA) and low InCanopy (LPIC) systems. LEPA systems (precision application) require adequate (implemented) soil, water and plant management. LPIC systems are used on lower value crops where localized water translocation is suitable, (30 feet before or behind the lateral position). Water is applied within the crop canopy through drop tubes fitted with low 5 - 10 psi application devices near the bottom surface. Good soil and water management are required to get application efficiencies within the high 80's. LPIC systems aren't suitable to be used on low intake soils. In New Jersey most center pivot systems are low, low volume systems with spray heads or rotator heads on drops. Each sprinkler features a pressure regulator set at $10-$ 20 psi. With proper management, application efficiencies with center pivot systems are often 75 - 90 percent counting on wind speed and direction, sprinkler type, operating pressure, and tillage practices. 


\section{5) Traveling Boom Sprinkler Systems ${ }^{[5]}$}

A traveling boom system is analogous to a traveling gun except several nozzles are used. These systems have higher distribution uniformity than traveling guns for an equivalent diameter of coverage. they're not as popular in NJ because the traveling gun system; however, do provide options when a grower prefers a lower volume and pressure systems to scale back the high energy costs related to a traveling gun system. The booms are often designed with low pressure and low flow nozzles that operate at higher efficiency and uniformity.

The traveling boom usually is rotated by back pressure from fixed nozzles, or could also be fixed. it's typically moved by a self-contained continuously moving electromagnetic unit by dragging or coiling the water feed hose on a reel. A boom are often nearly 100 feet long with uniformly spaced nozzles that overlap (similar to a linear move lateral).

6) Smartphone based Irrigation system ${ }^{[11]}$

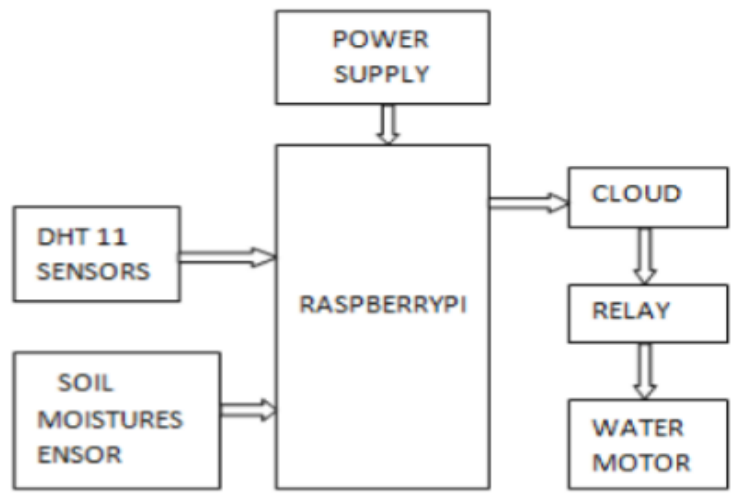

Fig. 4. Block diagram of Smartphone based Irrigation System ${ }^{[11]}$

Raspberry $\mathrm{Pi}$ is that the heart of the general existing system. The Raspberry Pi 3 incorporates variety of enhancements and new features. Improved power consumption, enlarged connectivity and greater IO are among the improvements to the present powerful, small and light-weight GPIO (General Purpose Input Output) pins. The Raspberry Pi cannot directly drive the relay. it's only zero volts or $3.3 \mathrm{~V}$. we'd like $12 \mathrm{~V}$ to drive the electromechanical relay. therein case, we'd like a driver circuit. the driving force circuits takes the low level input and provides the $12 \mathrm{~V}$. We are using here 2 relay to modify on Water motor. Soil moisture sensor, humidity sensor, temperature detection sensors are connected to Raspberry Pi board through Arduino. If the soil moisture value is low the moisture level and humidity is low at the given value and also if temperature is high then the water motors are going to be on, whereas if the moisture level, humidity is high and temperature is low the motor are going to be off throughout the relay. the appliance will have a GUI which can show all the info to user. The modes as specified are often selected by the user on the app itself.

\begin{tabular}{|c|c|c|c|}
\hline Method & Adapted To & Conservation Features & $\begin{array}{c}\text { Eff. } \\
\%\end{array}$ \\
\hline Linear Move & \multirow{6}{*}{$\begin{array}{l}\text { Nearly all crops on any } \\
\text { irrigable soils, except in very } \\
\text { windy hot climates. }\end{array}$} & $\begin{array}{l}\text { Provides good control of water applied. Good for } \\
\text { rectangular fields, may be equipped with drop tubes and } \\
\text { various spray heads to reduce wind drift and } \\
\text { evaporative losses and can operate on low pressures. }\end{array}$ & $75-90$ \\
\hline Center Pivot & & $\begin{array}{l}\text { Application uniformity is usually high, labor } \\
\text { requirements are low and pressure requirements are } \\
\text { often low. Results can be accomplished on fields which } \\
\text { are less than a full circle. }\end{array}$ & $75-90$ \\
\hline Fixed Solid Set & & $\begin{array}{l}\text { Labor requirements are low, easily automated and } \\
\text { application uniformity is usually high. }\end{array}$ & $60-75$ \\
\hline Side Rolls & & $\begin{array}{l}\text { Good for rectangular fields, not adapted to tall crops, } \\
\text { alignment may be difficult on undulating topography. }\end{array}$ & $60-75$ \\
\hline Hand Move & & $\begin{array}{l}\text { Good for irregular shaped hills and rolling terrain, not } \\
\text { suited for tall crops. More labor intensive than a side } \\
\text { roll system. }\end{array}$ & $60-75$ \\
\hline $\begin{array}{l}\text { Big Gun } \\
\text { (Traveling or } \\
\text { Stationary) }\end{array}$ & & $\begin{array}{l}\text { Good for irregular shaped fields, suited for high intake } \\
\text { rate soils, wind greatly affects water distribution } \\
\text { pattem. Manual labor minimized. }\end{array}$ & $55-65$ \\
\hline
\end{tabular}

Fig. 5. Different Methods and their Features ${ }^{[13]}$

\section{SOME RULES FOR SYSTEM DESIGN}

1) Main land should be at downhill.

2) Lateral should be laid across the slope or nearly on the contour.

3) For multiple lateral operation, lateral pipe sizes shouldn't be quite two diameter

4) water system source should be nearest to the middle of the world Layout should facilitate and minimize lateral movement during the season

5) Booster pump should be considered where small portion of field would require high at the pump

6) Layout should be modified to use different rates and amounts of water where soils are greatly different within the design area

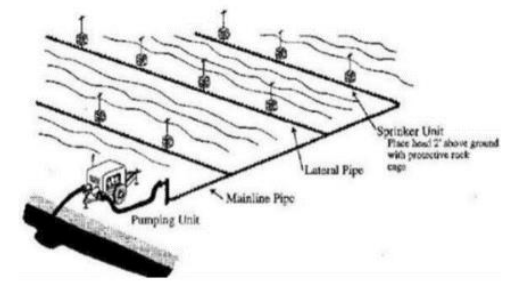

Fig. 6. Layout of the irrigation system design ${ }^{[6]}$

\section{IRRIGATION SYSTEM PLANNING AND DESIGN CONSIDERATION}

Proper system planning and style is important to Irrigation Water Management (IWM) and requires the thoughtful consideration of the many elements. Selecting a system must include the subsequent major items: Management, water, soil, and crops. ${ }^{[13]}$

a. Management:

The irrigator and planner got to collaborate so as to develop the simplest plan. The discussion of desired system type must include an understanding of management, operation, and maintenance requirements. [13]

b. Water:

The source, whether surface or ground, and therefore the quantity, quality, availability, and flow, are needed to work out the sort of system that's appropriate. Most 
sources of spring water require power, regardless of which sort of system is planned. With micro irrigation, a spring water source might only need an inline screen to wash the water while a surface water source would require a classy filtration system. Some sources, thanks to high salinity (EC), might not be suitable for sprinkler irrigation. A micro irrigation system works best with a continuing source while a surface system can operate an extended interval between water applications. A surface system is definitely requiring in a comparatively high flow for many efficient application, while sprinkler or micro irrigation systems can function well at a lower rate of application. [13]

c. Soil:

Many soil qualities are important when planning of an irrigation system is taken into consideration. Soil texture may be a good indicator of water holding capacity (whc), permeability, and transmissivity. Whe is especially important when considering a surface system, thanks to intervals between irrigations. Permeability plays an important role in surface system design, and to a lesser extent, sprinklers. Transmissivity, the power of water to maneuver through the soil, is vital when considering some extent source of irrigation, like with drip emitters. The water must be ready to enter and thru the basis zone.

d. Crops:

Selection of crops to be grown are often limited thanks to water quality and quantity. High salinity can cause yield reduction and even failure, depending upon the crop planted.

Other important considerations include season and site:

1. Season:

The length of season is vital for crop selection and is also important for justifying the expense for any system planned.

\section{Location:}

System structures and hardware must be ready to withstand climate extremes of temperature, humidity, precipitation, or wind. Proximity to wildlife, cattle, and humans also suggest necessary precautions to think about.

\section{SYSTEM OPERATION}

There are several ways to work the various sorts of travelling irrigation machines. The cable drawn travelling irrigator are going to be used as an example for instance the way travelers are operated. this technique possesses a trailer carrying the gun sprinkler. The trailer is additionally equipped with a water powered winch and a cable. The winch is then driven by water pressure from the pumping unit. Whereas, the gun sprinkler is supplied water from the pump, via a mainline, which has hydrants onto which the hose is connected. ${ }^{[2]}$

The following procedure is the way such a system is operated, step by step: ${ }^{[2]}$
1. The tractor, hose reel and irrigating unit are harnessed therein order along the tow-path

2. The cable is anchored at one end of the sector

3. Then the tractor is driven to the hydrant

4. Furthermore, the hose is then connected to the hydrant

5. Unwinding of the cable and hose are then done by driving the tractor to the opposite end of the sector.

6. subsequent step is to disconnect the hose

7. The hose reel and therefore the irrigating unit are then brought back to the primary position

8. The hose is attached to the irrigating unit and therefore the unit is additionally detached from the hose reel

9. As, the hose reel trailer is then driven to the position where the cable is anchored

10. The pump house should then be started.

The irrigating unit will then start to work, because it irrigates, it winds the cable on the winch and within the process moreover, it pulls itself on the cable.

Once it reaches the pre-determined distance on the brink of the opposite end, it automatically stops moving and irrigating. If this particular standing time is allowed for, it stops moving but continues to irrigate during the standing time. ${ }^{[2]}$

The following procedure should be followed when changing position to subsequent tow-path. ${ }^{[2]}$

1. The hose is disconnected from the hydrant also as from the irrigating unit

2. The hose is then further connected to the hose reel

3. The tractor should be connected to the hose reel before draining the hose by atmospheric pressure from a compressor

4. The hose is then rewound and therefore the equipment is moved to subsequent tow-path.

\section{CONCLUSION}

This review paper describes the basics of sprinkler irrigation, the performance of sprinkler systems including uniformity and efficiency of application, types, and characteristics of sprinkler systems currently used, and style and management procedures for specific sorts of sprinkler systems. Information is provided to reinforce the planning and management of sprinkler systems which are the foremost rapidly growing sort of irrigation today. The systems provide several benefits and it can operate with less manpower. The above mentioned systems supplies water on the humidity within the soil goes below the reference. Thanks to the direct transfer of water to the basis conservation takes place and also helps to take care of the moisture to soil ratio at the root zone constant to some extent. Thus the system is efficient and compatible to changing environment. The concept in future are often enhanced by adopting DTMF technology. This above mentioned methods are essentially hooked in to the output of the sensing arrangement. Whenever there's need of excess water within the desired field then it'll not be possible by using sensing arrangement technology. For this we'll need to adopt the DTMF technology. By using this we'll be ready to irrigate the specified field in desired amount. 


\section{REFERENCES}

[1] D. L. Martin, "Design and operation of sprinkle systems", DOI: 10.13031/2013.23699, 2007.

[2] A.P. Savva, J. Stoutjesdijk, P.M.A. Regnier, S.V. Hindkjaer, "Planning, Development Monitoring and Evaluation of Irrigated Agriculture with Farmer Participation", Food and Agriculture Organization of the United Nations (FAO) Sub-Regional Office for East and Southern Africa (SAFR), Vol. III, Module 8, 2001

[3] A. Phocaides, "Pressurized Irrigation Techniques", Food and Agriculture Organization of The United Nations, 2007.

[4] "Introduction to Microirrigation", Pradhan Mantri Krishi Sinchai Yojana (PMKSY) ,2019

[5] S.V. Hindkjaer, "Irrigation system design", (210-vi-NEH 652, IG Amend. NJ1, 06/2005)

[6] Bob Schultheis, "Sprinkler Irrigation" Missouri Minority \& Limited Resource Farmers' Conference, 2015.

[7] Stephanie Tam, Andrew Petersen, "SPRINKLER SYSTEM DESIGN", British Columbia, Ministry of Agriculture 2014.

[8] Bob Schultheis, "Basics of Irrigation System Design \& Maintenance", Missouri Minority \& Limited Resource Farmers' Conference, 2013.

[9] Anitha K, "AUTOMATIC IRRIGATION SYSTEM" $2^{\text {nd }}$ International Conference on Innovative trend in Science, Engineering and Management, ISBN: 978-93-86171-10-8, 2016.

[10] Pavithra D. S, M. S. Srinath., "GSM based Automatic Irrigation Control System for Efficient Use of Resources and Crop Planning by Using an Android Mobile", IOSR Journal of Mechanical and Civil Engineering (IOSR-JMCE), Volume 11, Issue 4 Ver. I (JulAug. 2014).

[11] Varsha P M, Varsha A, Shubhu H V, Parneeth charanthimath, "Smartphone based Automatic Irrigation System", International Journal of Engineering Research \& Technology, Vol. VI Issue 15, 2018.

[12] Nor Adni Mat Leh, Muhammad Syazwan Ariffudin Mohd, Zuraida Muhammad, "Smart Irrigation System Using Internet of Things", IEEE, 2019.

[13] Zakari, M.D.; Maina, M.M.; Abubakar, M.S.; Shanono, N.J.; Lawan, I.; Tadda, M.A. And Nasidi, N.M. "Design, Construction and Installation of Sprinkler Irrigation System", A Journal of the Faculty of Engineering, Vol VII, NO. 1 \& 2, 2014 